\title{
SARS-CoV-2; What We Know so far
}

\author{
Huda Fatima Rajani, MSc'; Fatima Ahmed Alshaikh, MSc ${ }^{2}$; Amir Anushiravani, $\mathrm{MD}^{3 *}$ \\ ${ }^{1}$ Department of Medical Biotechnology, School of Advanced Technologies in Medicine, Tehran University of Medical Sciences, Tehran, Iran \\ ${ }^{2}$ School of Medicine, Tehran University of Medical Sciences, Tehran, Iran \\ ${ }^{3}$ Digestive Diseases Research Institute, Tehran University of Medical Sciences, Tehran, Iran
}

\begin{abstract}
A recent outbreak of severe acute respiratory syndrome coronavirus 2 (SARS-CoV-2) has affected more than 1100000 (April 5, 2020) individuals worldwide and is spreading rapidly. The virus is reported to be derived from bats and the infection was first reported in China. Similar to the severe acute respiratory syndrome and the Middle East respiratory syndrome coronaviruses, it is responsible for respiratory tract infection. Real time polymerase chain reaction and radiography are the two main diagnostic methods. Guidelines from the Center for Disease Control and Prevention and the World Health Organization (WHO) should be followed for diagnostic and precautionary measures. Treatment of the infection is still not available; however, antivirals are under clinical trials.

Keywords: Antiviral agents, Radiography, Real-time polymerase chain reaction, SARS-CoV-2

Cite this article as: Rajani HF, Alshaikh FA, Anushiravani A. SARS-CoV-2; What we know so far. Arch Iran Med. 2020;23(7):498502. doi: 10.34172/aim.2020.47.
\end{abstract}

Received: April 3, 2020, Accepted: May 3, 2020, ePublished: July 1, 2020

\section{Introduction}

The coronavirus (CoV), from the family Coronaviridae, is an enveloped plus-strand RNA virus that causes a range of diseases from the common cold to fatal severe acute respiratory syndrome (SARS) and Middle East respiratory syndrome (MERS) among humans. Previously, four types of coronavirus HCoV-OC43, HCoV229E, SARS$\mathrm{CoV}$, and MERS-CoV had been reported. ${ }^{1,2}$ Following the discovery of SARS and MERS types in China and the Middle East, respectively, the virus is known to be dangerous and able to lead to fatality. The SARS coronavirus utilizes angiotensin converting enzyme 2 receptors (ACE2) to infect unciliated bronchial epithelial cells and type II pneumocytes. ${ }^{3}$ It may also attach to other organs that have ACE2 receptors. The MERS-CoV uses CD26 (also known as Dipeptidyl peptidase-4 or adenosine deaminase complexing protein 2) to infect the same cells as SARS-CoV. ${ }^{2}$ These are transmitted from civets and camels, respectively, and are known to have their origin from bats. ${ }^{1}$ The mortality rate of SARS-CoV is reported to be $10 \%$ whereas it is $37 \%$ for the MERS coronavirus. ${ }^{4}$

A recent outbreak of coronavirus (sarbecovirus subgenus $)^{5}$ identified as SARS-CoV-2 has been reported to be initiated in China and is now reported extensively in several other regions of the world including Italy, Iran, the United States and 202 other countries/territories/ areas according to a recent report by the World Health Organization (WHO). Globally, 1133758 cases have been confirmed with 62784 deaths until 5 April $2020 .^{6}$
Several manifestations of the infection have been reported to be similar to those of SARS and MERS such as respiratory infection, cytokine storm and lung injury. However, a number of pathologically unique findings have given this infection a unique nature. ${ }^{4}$ The SARS-CoV-2 is genetically $96.3 \%$ similar to the RaTG13 sequence of the bat-coronavirus (BatCoV). Bioinformatic analysis has revealed that SARS-CoV-2 is not a variant of BatCoV but BatCoV itself.

The aim of this review is to evaluate the clinical findings associated with the recent COVID-19 causing SARS$\mathrm{CoV}-2$ using the information available.

\section{Symptoms and Diagnosis}

Symptomatic patients present with fever (78.75\%), with or without tachycardia, cough $(63.75 \%)$ with or without chest discomfort, respiratory distress (14\%), nausea and vomiting $(1.25 \%)$, chest pain $(3.75 \%)$, loose stool (1.25\%) (Rare cases), muscle pain (22.5\%), headache (16.25\%) and hemoptysis. ${ }^{4,5,8}$ Additionally, cardiovascular and cerebrovascular disease (31.25\%) may also be seen in these patients. ${ }^{4}$

\section{Real-Time Polymerase Chain Reaction}

A novel outbreak of pneumonia was reported initially in a group of Chinese people known to be associated with the seafood animal market in Wuhan, China. Tests from these patients showed positive findings for a pneumoniacausing coronavirus, reported by the Chinese Center for

*Corresponding Author: Amir Anushiravani, MD; Jalal Al Ahmad St., Shariati Hospital, Digestive Disease Research Institute, Tehran University of Medical Science es, Tehran, Iran. Postal Code: 14117-13135; Tel: +98-21-82415000; Fax: +98-21-82415000; Email: amiranush@gmail.com 
Disease Control and Prevention. Real time polymerase chain reaction (RT-PCR) on bronchoalveolar-lavage fluid samples was used to detect the CoV RNA RdRp domain of the virus. The genome was found to be $85 \%$ similar to that of bat SARS-like CoV (betacorona virus). Additionally, the virus was isolated from the nasal fluid by culture of human epithelial airway cells. Cytopathic effects of the virus in the cells were seen in the form of cilium beating. The size of the virus using electron microscopy was reported to be $60-140 \mathrm{~nm}$ and spike projections of $9-12 \mathrm{~nm}$ were visualized. ${ }^{5}$ Based on WHO recommendations, upper and lower respiratory tract samples are required to be obtained and RT-PCR for SARS-CoV-2 (primers and probes) as per PCR conditions described. ${ }^{9}$ The total RNA can also be extracted from patients' plasma. ${ }^{4}$

\section{Radiological Findings}

Maximum lung involvement is usually seen 10 days after the onset of the symptoms. ${ }^{10}$ Chest radiography and CT scan present the evidence of pneumonia. ${ }^{8} \mathrm{CT}$ findings are characterized by bilateral ground-glass opacity which may consolidate after approximately 8 days ${ }^{4}$ and the involvement of more than two lobes. ${ }^{11}$ A report by Pan et al ${ }^{10}$ stated four different recovery stages of the lung involvement based on the findings from CT scan on different days; ground glass opacity, increased crazy-paving pattern, consolidation and gradual resolution of consolidation. The study also reported that lung involvement is maximum within two weeks of the onset of symptoms.

\section{Laboratory Findings}

According to the recommendation by the Center for Disease Control and Prevention (CDC), if favorable climatic conditions are present, the COVID-19 test should be conducted outdoors. ${ }^{12}$ Complete blood count of the patient is likely to show no changes in the levels of lymphocytes or lymphopenia in some cases. ${ }^{4,8}$ Nonetheless, a retrospective study conducted on 138 cases in Wuhan, China reported lymphopenia in 97 patient. ${ }^{13}$ Patients admitted to the ICU are known to present with increase in prothrombin time and D-dimer, as well as aspartate aminotransferase and lactate dehydrogenase levels. However, comorbidities are likely to be associated with these lab findings. Plasma inflammatory cytokines such as IL-2, IL-7, IL-10, TNF-a (tumor necrosis factoralpha) and G-SCF (granulocyte-colony stimulating factor) are elevated in critically ill patients. ${ }^{4}$

\section{Potential Risk Factors}

According to a study by $\mathrm{Li}$ et $\mathrm{al}^{9}$ on 425 patients affected in Wuhan, China, the mean age of patients was 59 years and $56 \%$ of the patients were male. However, the study also reported that early onset of COVID-19 was common in younger patients. Furthermore, every infected patient was likely to infect 2.2 individuals - one of the significant causes of an increase in the epidemic.

Another study by Huang et $\mathrm{al}^{4}$ reported data from 41 COVID-19 positive patients admitted to hospitals in Wuhan. The mean age of patients was 49.0 years and $73 \%$ of them were men. Of $32 \%$ of the patients with underlying disease, $20 \%$ had diabetes, $15 \%$ had hypertension and another $15 \%$ had cardiovascular disease. Furthermore, $66 \%$ of the patients had been to the Huanan seafood market. Thirty-two percent of the patients were critically ill (hypoxemia) and required extensive oxygen support. Zhang et $\mathrm{al}^{14}$ presented the clinical characteristics of 140 COIVD-19 patients and concluded that allergic disease, chronic obstructive pulmonary disease and asthma might not be risk factors for the infection. The study also reported that presence of comorbidities in older patients made them highly susceptible to the infection and its severity.

Individuals, including intimate partners, living in the same household settings as confirmed COVID-19 patient are at high risk of contracting the infection. Asymptomatic low-risk patients (in the same indoor environment as the patient, without any close contact) are required to observe for symptoms (fever in particular) for 14 days. ${ }^{12}$

\section{Treatment}

The incubation and quarantine periods for SARS-CoV-2 positive patients are suggested to be 1-14 days. ${ }^{9}$ Treatment is usually initiated by broad spectrum anti-virals including oseltamivir, Lopinavir /Ritonavir, nucleoside analogues, neuraminidase inhibitors, and remdesivir, peptide. Additional oxygen support is provided if needed. Associated complications and secondary infections may be treated by steroids, anti-inflammatory drugs and antibiotics, depending on the patient's condition., ${ }^{4,15}$

Animal studies have been conducted on the effect of nucleoside analogues remdesivir and galidesivir against SARS-CoV-2. ${ }^{16}$ Remdesivir (GS-5734) is a broad-spectrum adenosine analogue, which is used against RNA viruses for the treatment of SARS and MERS coronavirus. It integrates into viral RNA and terminates the transcription process. An experimental study on non-human primates has shown that at the concentration of $10 \mathrm{mg} / \mathrm{kg}$, remdesivir eradicates Ebola infection and inhibits coronavirus-2019 infection in human liver cancer cell line. Similarly, chloroquine, an antimalarial, blocks glycosylation and viral/cell fusion in SARS-CoV. In vitro studies have shown its efficacy against SARS-CoV-2 in Vero E6 cells. ${ }^{17}$ Since SARS-CoV-2 uses the angiotensin converting enzyme receptor as an entry route, similar to SARS-CoV, chloroquine as ACE inhibitors is likely to be therapeutically potent against COVID-19 causing SARS-CoV-2. ${ }^{18,19}$ Intravenous remdesivir is in phase III of clinical trial, and results are expected by April 2020. Other antivirals especially those against hepatitis $\mathrm{C}$ virus and SARS and MERS coronavirus are also hypothesized to be effective 
against the infection; nonetheless, experimental and clinical studies are required to optimize the therapeutic dose and determine clinical efficacy and associated side effects. ${ }^{16}$

As per the guidelines of the Iranian Ministry of Health, one of the following therapeutic regimens is recommended to be used against the infection: hydroxychloroquine sulfate $400 \mathrm{mg}$ (single dose) and lopinavir/ritonavir 400 $\mathrm{mg} / 100 \mathrm{mg}$ (BD for 5 days) or hydroxychloroquine sulfate $200 \mathrm{mg}$ (BD for 14 days).

\section{Transmission and Precautions}

The process of human-to-human transmission of virus still remains a question. ${ }^{20}$ However, it is suggested that the virus can be transmitted via droplets and contact. Many environmental surfaces have also been tested for viral RNA within five days of the last positive test via respiratory samples. The live virus is also found in fecal matter, perhaps due to the expression of ACE2 receptors in the intestines, and it is hypothesized that the virus can be transmitted via the fecal-oral route, similar to SARS$\mathrm{CoV}$ and MERS-CoV. The infective droplets can also come in contact with ocular surfaces, where the infection can begin in the form of conjunctivitis. ${ }^{21}$ Transmission has been also reported from asymptomatic patients with normal CT scan. ${ }^{22}$ Vertical transmission of the virus from COVID-19 positive mothers to fetus in the uterus has not been reported. ${ }^{23}$

Patients with or suspected of an infection are recommended to be kept in AIIR (airborne infection isolation room), which has negative air pressure. At least six air changes per hour is suggested for the room by CDC. Health care practitioners are advised to use disposable patient care supplies such as blood pressure hand cuffs, gowns and gloves. Additionally, hands should be washed with soap or water for 20 seconds. The use of N95 respirators are strongly advised that should be fit-tested. Following the diagnostic test and exposure to symptomatic or asymptomatic patient, $60 \%-95 \%$ alcohol should be used for hand hygiene. ${ }^{15}$ Fitted N95 masks are recommended in COVID-19 patients to reduce air-borne transmission. Immediate clinical assessment of patients presenting with symptoms is strongly recommended. Additionally, health care workers should also be tested using serum antibodies. ${ }^{4}$ Use of masks is recommended in healthy people only in case of their contact with SARS-CoV-2 suspected patients. Individuals who cough and sneeze are recommended to use masks, as per WHO guidelines. Before the application of mask, hand hygiene should be observed and frequent touching of mask should be avoided. Hand hygiene should also be observed when removing or touching the mask. One-meter distance should be kept from an individual who sneezes or coughs. ${ }^{24}$

\section{Conclusion and Prospective Remarks}

COVID-19, with a lower case-fatality rate, has been reported to have a greater number of fatalities than SARS and MERS, possibly due to the transmission from asymptomatic patients.

As per the data provided by the WHO, within a period of a month, a drastic increase has been seen in the number of cases and fatalities (Figure 1). Extrapolation of the available data clearly predicts a total of 2689781 cases and 71694 deaths within the next few days (until April 20, 2020) (Figures 2 and 3). Unavailability of medical measures including quarantine, isolation, hand sanitizers, masks and medications has imposed a great socioeconomic and health burden. Clearly, the world was not prepared for this catastrophic outbreak. Reporting from the Islamic Republic of Iran, until now (April 5, 2020), 55743 cases and 3452 fatalities have been reported, activities and business have shut down, fear of infection has left people home-bound and international flights from the region have stopped to a greater extent. The question is, how long will this situation continue? Although maximum measures are taken, why are they still insufficient? All eyes are on the clinical trials on antivirals and vaccines, and the world seems to stop until further notice or therapeutic decision.

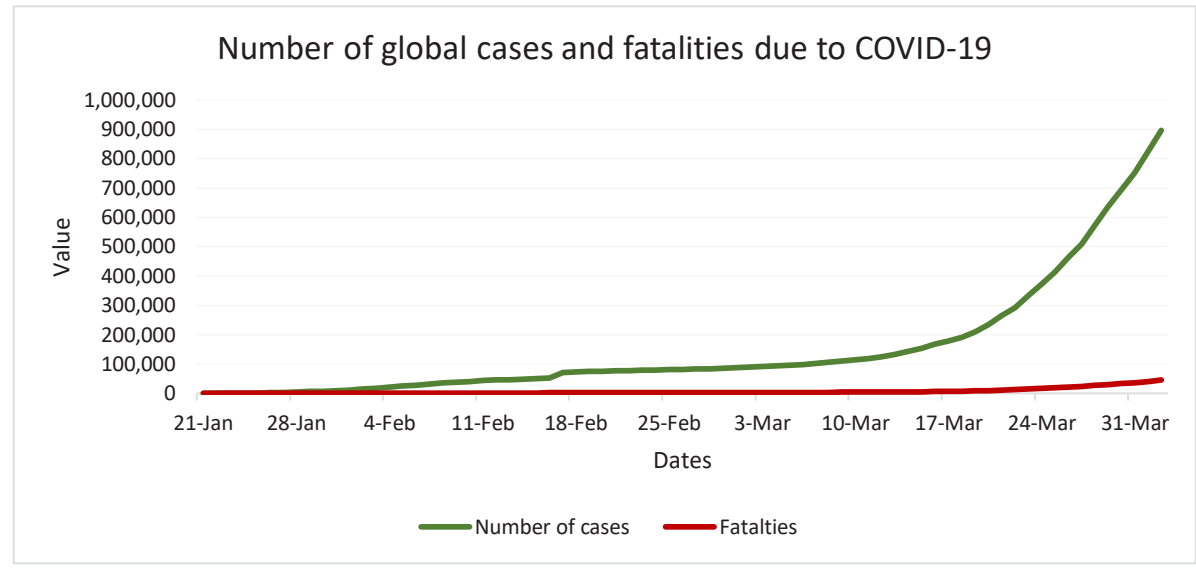

Figure 1. Overall Number of Cases and Fatalities due to COVID-19. 


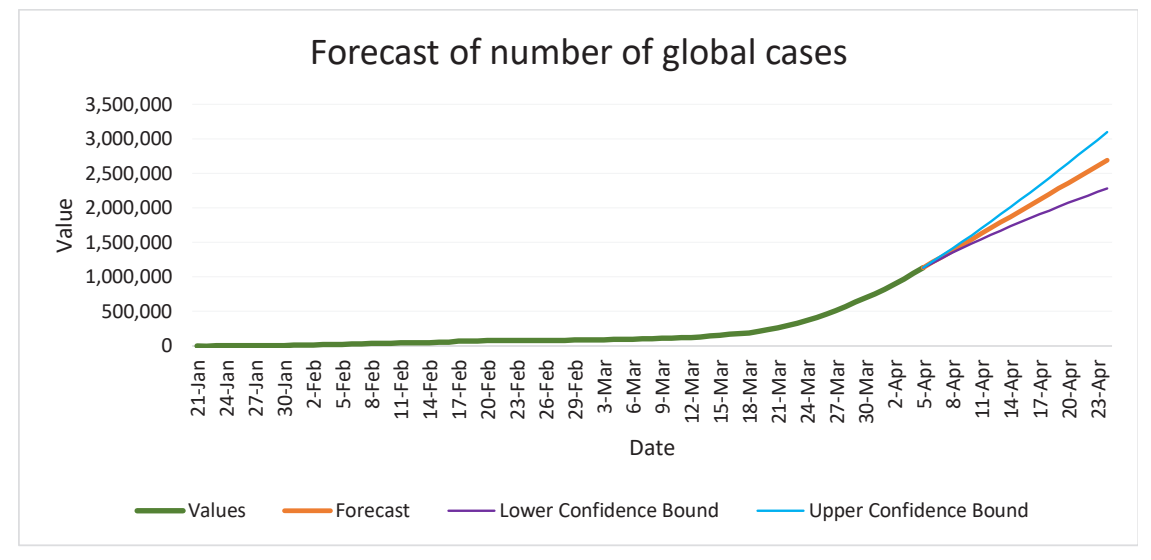

Figure 2. Forecast of Global COVID-19 Cases.

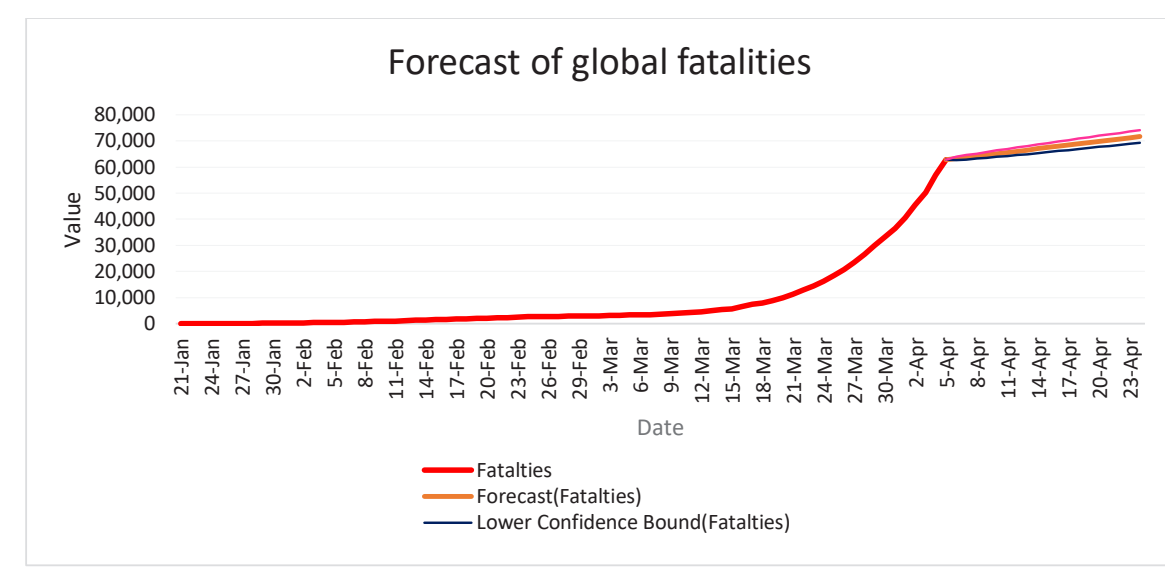

Figure 3. Forecast of Global Fatalities due to COVID-19.

\section{Authors' Contribution}

HFR and FAA participated in data gathering and designing the study. All authors contributed to writing the article and approved the final format.

\section{Conflict of Interest Disclosures}

The authors declare no competing interests.

\section{Ethical Statement}

Not applicable.

\section{References}

1. Cui J, Li F, Shi, ZL. Origin and evolution of pathogenic coronaviruses. Nat Rev Microbiol. 2019;17(3):181-2. doi: 10.1038/s41579-018-0118-9.

2. van der Hoek L, Pyrc K, Jebbink MF, Vermeulen-Oost W, Berkhout RJ, Wolthers KC, et al. Identification of a new human coronavirus. Nat Med. 2004;10(4):368-73. doi: 10.1038/ nm1024.

3. Li W, Moore MJ, Vasilieva N, Sui J, Wong SK, Berne MA, et al. Angiotensin-converting enzyme 2 is a functional receptor for the SARS coronavirus. Nature. 2003;426(6965):450-4. doi: 10.1038/nature02145.

4. Huang C, Wang Y, Li X, Ren L, Zhao J, Hu Y, et al. Clinical features of patients infected with 2019 novel coronavirus in Wuhan, China. Lancet. 2020;395(10223):497-506. doi: 10.1016/S0140-6736(20)30183-5.

5. Zhu N, Zhang D, Wang W, Li X, Yang B, Song J, et al. A Novel Coronavirus from Patients with Pneumonia in China, 2019. N Engl J Med. 2020;382(8):727-33. doi: 10.1056/
NEJMoa2001017.

6. WHO. Coronavirus disease 2019 (COVID-19): Situation Report-76. Available from: https://www.who.int/docs/defaultsource/coronaviruse/situation-reports/20200405-sitrep-76covid-19.pdf?sfvrsn=6ecf0977_4. 5 April 2020.

7. Paraskevis D, Kostaki EG, Magiorkinis G, Panayiotakopoulos G, Sourvinos G, Tsiodras S. Full-genome evolutionary analysis of the novel corona virus (2019-nCoV) rejects the hypothesis of emergence as a result of a recent recombination event. Infect Genet Evol. 2020;79:104212. doi: 10.1016/j. meegid.2020.104212.

8. Holshue M L, DeBolt $\mathrm{C}$, Lindquist $\mathrm{S}$, Lofy $\mathrm{K} \mathrm{H}$, Wiesman J, Bruce $\mathrm{H}$, et al. First case of 2019 novel coronavirus in the United States. N Engl J Med. 2020;382(10):929-36. doi: 10.1056/NEJMoa2001191.

9. Li Q, Guan X, Wu P, Wang X, Zhou L, Tong Y, et al. Early transmission dynamics in Wuhan, China, of novel coronavirusinfected pneumonia. N Engl J Med. 2020;382(13):1199-207. doi: 10.1056/NEJMoa2001316.

10. Pan F, Ye T, Sun P, Gui S, Liang B, Li L, et al. Time course of lung changes at chest CT during recovery from coronavirus disease 2019 (COVID-19). Radiology. 2020;295(3):715-21. doi: 10.1148/radiol.2020200370.

11. Chung M, Bernheim A, Mei X, Zhang N, Huang M, Zeng $X$, et al. CT Imaging features of 2019 novel coronavirus (2019-nCoV). Radiology. 2020;295(1):202-7. doi: 10.1148/ radiol.2020200230.

12. CDC. Interim Infection Prevention and Control Recommendations for Patients with Suspected or Confirmed Coronavirus Disease 2019 (COVID-19) in Healthcare Settings. 
Available from: https://www.cdc.gov/coronavirus/2019-ncov/ hcp/infection-control-recommendations.html. May 18, 2020.

13. Wang D, Hu B, Hu C, Zhu F, Liu X, Zhang J, et al. Clinical characteristics of 138 hospitalized patients with 2019 novel coronavirus-infected pneumonia in Wuhan, China. JAMA. 2020;323(11):1061-9. doi: 10.1001/jama.2020.1585.

14. Zhang JJ, Dong $X$, Cao YY, Yuan YD, Yang YB, Yan YQ, et al. Clinical characteristics of 140 patients infected with in Wuhan, China. Allergy. 2020. doi: 10.1111/all.14238.

15. Wong SK, Li W, Moore MJ, Choe H, Farzan M. A 193-amino acid fragment of the SARS coronavirus $\mathrm{S}$ protein efficiently binds angiotensin-converting enzyme 2. J Biol Chem. 2004;279(5):3197-201. doi: 10.1074/jbc.C300520200.

16. Li G, De Clercq E. Therapeutic options for the 2019 novel coronavirus (2019-nCoV). Nat Rev Drug Discov. 2020;19(3):149-50. doi: 10.1038/d41573-020-00016-0.

17. Wang M, Cao R, Zhang L, Yang X, Liu J, Xu M, et al. Remdesivir and chloroquine effectively inhibit the recently emerged novel coronavirus (2019-nCoV) in vitro. Cell Res. 2020;30(3):26971. doi: 10.1038/s41422-020-0282-0.

18. Adedeji AO, Severson W, Jonsson C, Singh K, Weiss SR, Sarafianos SG. Novel inhibitors of severe acute respiratory syndrome coronavirus entry that act by three distinct mechanisms. J Virol. 2013;87(14):8017-28. doi: 10.1128/ JVI.00998-13.
19. Zhou P, Yang XL, Wang XG, Hu B, Zhang L, Zhang W, et al. A pneumonia outbreak associated with a new coronavirus of probable bat origin. Nature. 2020;579(7798):270-3. doi: 10.1038/s41586-020-2012-7.

20. Phan LT, Nguyen TV, Luong QC, Nguyen TV, Nguyen HT, Le $\mathrm{HQ}$, et al. Importation and human-to-human transmission of a novel coronavirus in Vietnam. N Engl J Med. 2020;382(9):87274. doi: 10.1056/NEJMc2001272.

21. Han $\mathrm{Y}$, Yang $\mathrm{H}$. The transmission and diagnosis of 2019 novel coronavirus infection disease (COVID-19): a Chinese perspective. J Med Virol. 2020;92(6):639-44. doi: 10.1002/ jmv.25749.

22. Bai Y, Yao L, Wei T, Tian F, Jin DY, Chen L, et al. Presumed asymptomatic carrier transmission of COVID-19. JAMA. 2020;323(14):1406-7. doi: 10.1001/jama.2020.2565.

23. Chen H, Guo J, Wang C, Luo F, Yu X, Zhang W, et al. Clinical characteristics and intrauterine vertical transmission potential of COVID-19 infection in nine pregnant women: a retrospective review of medical records. Lancet. 2020;395(10226):809-15. doi: 10.1016/S0140-6736(20)30360-3.

24. WHO. Coronavirus disease (COVID-19) advice for the public: When and how to use masks. Available from: https://www. who.int/emergencies/diseases/novel-coronavirus-2019/ advice-for-public/when-and-how-to-use-masks. 17 June 2020. 